\title{
As nanotecnologias no panorama regulatório: entre a ausência de regulação estatal específica e a necessidade de harmonização regulatória não estatal ${ }^{1}$
}

\section{Nanotechnologies in regulatory overview: between the regulation of state specific absence and the harmonization need of the not state regulatory}

\author{
Wilson Engelmann ${ }^{2}$ \\ Ronei Leonardo Pulz ${ }^{3}$ \\ Universidade do Vale do Rio dos Sinos (Brasil)
}

Recibido: 31-01-15

Aprobado: 20-02-15

\section{Resumo}

Este trabalho investiga o desenvolvimento das nanotecnologias, como um exemplo das chamadas "novas tecnologias", que prometem revolucionar a vida humana sobre a face da Terra. As normatizações ético-jurídicas dos resultados da

\footnotetext{
${ }^{1}$ Resultado parcial da pesquisa desenvolvida no âmbito dos seguintes projetos de pesquisa: (a) Chamada $\mathrm{MCTI} / \mathrm{CNPq} \mathrm{N}{ }^{\circ}$ 17/2011 - Apoio à criação de redes cooperativas de pesquisa e desenvolvimento em Nanotoxicologia e Nanoinstrumentação: projeto intitulado: "Nanotoxicologia ocupacional e ambiental: subsídios científicos para estabelecer marcos regulatórios e avaliação de riscos"; (b) Nanocosméticos e o Direito à Informação: construindo elementos e condições para aproximar o desenvolvimento tecnocientífico na escala nano da necessidade de informar o público consumidor - Edital Pesquisador Gaúcho - FAPERGS.

2 (wengelmann@unisinos.br). Doutor e Mestre em Direito pelo Programa de Pós-Graduação em Direito - Mestrado e Doutorado - da Universidade do Vale do Rio dos Sinos (São Leopoldo/RS/Brasil); professor deste mesmo Programa; Bolsista de Produtividade em Pesquisa do CNPq. Publicações: Engelmann, W., Borges, G. S.: Responsabilidade Civil médica pela utilização da nanotecnologia para modificação genética. Revista de Direito do Consumidor, v. 93, p. 65-100, 2014; Engelmann, W., Hohendorf, R. V., Schaffer, M. H.: Nanotechnology as a privileged example of technological innovation: building the foudations for the design of the 'quadruple helix'. Novos Estudos Jurídicos (Online), v. 19, p. 839-876, 2014; Hohendorf, R. V., Engelmann, W.: Nanotecnologias Aplicadas aos Agroquímicos no Brasil: a gestão dos riscos a partir do Diálogo entre as Fontes do Direito. 1 ${ }^{\mathrm{a}}$. ed. Curitiba: Juruá Editora, 2014. v. 1. 229 p.

${ }^{3}$ (roneipulz@terra.com.br). Mestrando em Direito Público pelo Programa de Pós-Graduação em Direito - Mestrado e Doutorado - da Universidade do Vale do Rio dos Sinos (São Leopoldo/RS/Brasil).
} 
escala nano ainda são incipientes, embora sejam absolutamente necessárias. Pretende-se destacar a importância da participação do Direito, como uma das áreas das Ciência de Impactos, neste cenário de inovação. Existe uma dificuldade legislativa de se regular a matéria. $\mathrm{O}$ artigo aponta o diálogo entre as fontes do Direito como uma nova forma de se desenvolver as respostas jurídicas para as nanotecnologias, a partir das produções normativas geradas por agências e organismos internacionais, que já estão expedindo recomendações, standards e orientações, como novas formas de regulação, que deverão ser harmonizadas, dada a grande quantidade destes textos já disponíveis.

Palabras-chave: Nanotecnologias, Novas Tecnologias, Regulação, Diálogo entre as Fontes do Direito.

\begin{abstract}
This paper investigates the development of nanotechnology, as an example of so-called "new technologies" that promise to revolutionize human life on earth. The ethical and legal norms of the nano-scale results are still preliminary, although they are absolutely necessary. The aim is to highlight the importance of participation of law, as an area of Impacts of Science, in this scenario of innovation. There is a legislative difficulty of regulating the matter. The article points out the dialogue between the sources of law as a new way to develop legal responses to nanotechnology, from the normative productions generated by international agencies and organizations, which are already issuing recommendations, standards and guidelines, as new forms of regulation, which should be harmonized, given the large amount of these texts already available.
\end{abstract}

Key-words: Nanotechnology, New Technologies, Regulation, Dialogue between the Sources of Law.

\title{
1. À guisa de introdução: a emergência do mundo das novas tecnologias
}

As novas tecnologias sugerem um cenário contemporâneo repleto de benefícios e tamanho avanço para a humanidade que surpreende dia-a-dia, seja pelas inovações percebidas pelo desenvolvimento econômico como também pela sua contribuição nos riscos e desastres por acidentes tecnológicos.

Nesse sentido, a "técnica moderna introduziu ações de uma tal ordem inédita de grandeza, com tais novos objetos e consequências que a moldura da ética antiga não consegue mais enquadrá-las". ${ }^{4}$ A sociedade se encontra

${ }^{4}$ Hans Jonas, O princípio da responsabilidade: ensaio de uma ética para a civilização tecnológica Araucaria. Revista Iberoamericana de Filosofía, Política y Humanidades, año 17, n 33. Primer semestre de 2015. Pp. 151-181. ISSN 1575-6823 e-ISSN 2340-2199 doi: 10.12795/araucaria.2015.i33.07 
definitivamente na fase nanotecnológica, uma etapa avançada das novas tecnologias, que carrega desafios sem precedentes para todas as áreas do conhecimento, incluindo o Direito. De acordo com Tiago Fensterseifer ${ }^{5}$ :

O atual estágio do conhecimento humano alterou significativamente a relação de forças existente entre o ser humano e a Natureza. Se há alguns séculos atrás o poder de intervenção do ser humano no meio natural era limitado, prevalecendo esta relação de forças em favor da Natureza, hoje a balança se inverteu de forma definitiva. O ser humano, em vista do aparato tecnológico desenvolvido ao longo, principalmente, dos dois últimos séculos, concentrou tamanho poder de intervenção e alteração das condições naturais que a natureza da sua ação sofreu profundas alterações, expondo, em grande medida, a própria sobrevivência da espécie humana (grifo nosso).

A sociedade contemporânea é marcada pelo enorme avanço tecnológico e econômico, ditado pelas novas formas industriais. Vive-se um processo de transição industrial para uma formatação pós-industrial, permeada de riscos e incertezas oriundas da complexidade das relações e das atividades humanas. Um foco de preocupação deverá ladear este cenário: as novas tecnologias são boas e necessárias para o bem-estar humano?

"Somos tentados a crer que a vocação dos homens se encontra no contínuo progresso desse empreendimento, superando-se sempre a si mesmo, rumo a feitos cada vez maiores. A conquista de um domínio total sobre as coisas e sobre o próprio homem [...]" ${ }^{6}$. Entretanto, nesse processo de desenvolvimento tecnológico, é "fundamental entender os interesses que estão subsidiando essas novas tecnologias". ${ }^{7}$ Por isso, que se coloca a pergunta anterior: para quem servirá o avanço tecnológico?

"A luz de tal perspectiva, o uso de tecnologias, por vezes, expõe a existência humana a tal ponto em que o ser humano é colocado como meio ou objeto para a consecução de determinadas praticas". ${ }^{8}$ Deve-se, pois, focar nas reflexões éticas sobre os efeitos oriundos da evolução desenfreada de tecnologias, do contexto cultural e consumista vivenciado e do risco do mau uso da ciência, ou

[Hans Jonas; tradução do original alemão Marijane Lisboa, Luiz Barros Montez], Rio de Janeiro, Contraponto Ed. PUC-Rio, 2006, pág. 39.

${ }^{5}$ Tiago Fensterseifer, Direitos fundamentais e proteção do ambiente: a dimensão ecológica da dignidade humana no marco jurídico constitucional do estado socioambiental de direito. Porto Alegre, Livraria do Advogado, 2008, pág. 58.

${ }^{6}$ Hans Jonas, O princípio da responsabilidade: ensaio de uma ética para a civilização tecnológica [Hans Jonas; tradução do original alemão Marijane Lisboa, Luiz Barros Montez], Rio de Janeiro, Contraponto Ed. PUC-Rio, 2006, pág. 43.

${ }^{7}$ Eliane Cristina P. Moreira, Nanotecnologia e regulação: as inter-relações entre o Direito e as ciências. [MARTINS, Paulo Roberto (org.)], Nanotecnologia sociedade e meio ambiente, São Paulo, Xamã, 2006, pág. 309.

${ }^{8}$ Tiago Fensterseifer, Direitos fundamentais e proteção do ambiente: a dimensão ecológica da dignidade humana no marco jurídico constitucional do estado socioambiental de direito, Porto Alegre, Livraria do Advogado, 2008, pág. 58.

Araucaria. Revista Iberoamericana de Filosofía, Política y Humanidades, año 17, $\mathrm{n}^{\circ} 33$. Primer semestre de 2015. Pp. 151-181. ISSN 1575-6823 e-ISSN 2340-2199 doi: 10.12795/araucaria.2015.i33.07 
ainda, de infligir sofrimento a outros seres e espécie para obtenção da satisfação e uso dessas novas tecnologias. Como se verá, é nesse cenário que se inserem as nanotecnologias. Conforme elucida Esper A. Cavalheiro'

As perspectivas abertas pela Convergência Tecnológica são imensas, mas não são menores os temores que ela inspira para os mais pessimistas. Seus desafios parecem atrair, atualmente, os melhores cérebros do mundo e mobilizar paixões intensas, assim como extensos interesses. [...] O certo é que a Convergência Tecnológica abre possibilidades e encerra dilemas éticos importantes demais para que seu monopólio pertença a quem quer que seja, inclusive a cientistas. Deve, portanto, interessar, implicar e mobilizar todos nós. Porque, para além de ser um tema de interesse para a ciência de ponta, certamente pressupõe dimensões de uma nova cidadania planetária (grifo nosso).

As promessas de benefícios da ciência e tecnologia são muito sedutoras, contudo nem sempre é de fato a melhor opção. "Nos primórdios de uma nova tecnologia, declarações e manifestos em tom de ficção científica são bastante comuns, inclusive com o surgimento de 'gurus' vindos do próprio meio científico"10, o que não quer dizer o contrário. Tudo depende da forma como são conduzidos e levantados os questionamentos acerca das promessas. De igual modo, descreve Peter Schulz ${ }^{11}$ :

Em relação às novas tecnologias desse início de século não se imagina implantar obrigatoriedades e usos da força, mecanismos mais sutis de aliciação não deixam de ser usados. $O$ discurso muito entusiasmado é um dos sintomas, bem como o extremamente pessimista. Ambos usam a desinformação" (grifo nosso).

Mais uma vez, pensamentos que refletem na necessidade de marcos regulatórios, reflexões éticas e participativas da sociedade, eis que, em ciência não se pode afirmar nada com certeza absoluta, a ciência não funciona com verdades finais, tem-se o que se conhece hoje e o que se pode medir hoje, para isso se precisa da tecnologia.

É fundamental a existência de certas perguntas que não tenham respostas ou que sejam muito difíceis de serem respondidas, por esta razão que se continua incessantemente investigando os eventos da natureza, por meio da ciência e da tecnologia, movidas pela inquietação do homem e do não saber. É

\footnotetext{
${ }^{9}$ Esper A. Cavalheiro, A nova convergência da ciência e da tecnologia. Novos estudos - CEBRAP, n.78, p. 23-30. 2007. Disponível em: <http://www.scielo.br/pdf/nec/n78/04.pdf>. Acesso em: 08 fev. 2015.

${ }^{10}$ Peter Alexander Bleinroth Schulz, A encruzilhada da nanotecnologia: inovação, tecnologia e riscos, Rio de Janeiro, Vieira \& Lent, 2009, pág. 92.

${ }^{11}$ Ibid., p. 94.
} 
nesse sentido o entendimento de Gadamer: "[...] a essência da pergunta é a de abrir e manter abertas possibilidades. [...]". É nesse contexto, igualmente, que se projeta outro elemento constitutivo da compreensão do mundo circundante: "[...] horizonte é o âmbito de visão que abarca e encerra tudo o que é visível a partir de um determinado ponto. [...] A elaboração da situação hermenêutica significa então a obtenção do horizonte de questionamento correto para as questões que se colocam frente à tradição". ${ }^{12}$ Por isso, especialmente no caso das novas tecnologias, o mais adequado é buscar as perguntas e trazê-las à tona, iluminadas pelas orientações emergentes da tradição. Este é o viés metodológico que sustenta este trabalho, mostrando que o "fenômeno" das nanotecnologias se encontra no mundo que circunda cada ser humano, sendo que deverá ser interpretado, recebendo a atribuição de sentido neste próprio "locus". Não se trata de algo alheio aos autores, mas um fenômeno que atinge diretamente a sociedade e os seus integrantes. Por isso, a necessidade de seu estudo, com a atribuição jurídica de sentido.

O problema que este trabalho pretende enfrentar poderá ser assim delineado: sob quais condições o diálogo entre as fontes do Direito poderão aproximar as nanotecnologias das Ciências de Impacto, buscando respostas jurídicas temporalmente adequadas?

A hipótese tem o seguinte arcabouço: urge a regulação, meio a ser utilizado para controlar questões sociais, políticas e éticas dessa tecnologia. No entanto, a regulação já existe, mas não no formato conhecido por meio do texto de lei. A regulação expressa por meio de portarias, recomendações, orientações e standards, que são editados por órgãos e agências, sendo o diálogo entre as fontes um modelo para se construir respostas jurídicas rápidas e flexíveis, em consonância com os avanços nanotecnológicos.

\section{O mundo das nanotecnologias: um exemplo privilegiado de novas tecnologias}

"Nano" é uma medida, é um prefixo de origem grega e significa anão. É a mesma origem da palavra nanica. Em um conceito simples "nanotecnologia - é a investigação e manipulação controlada da matéria em uma escala nanométrica." ${ }^{13} \mathrm{O}$ mais adequado é utilizar a expressão no plural, ou seja, "nanotecnologias", pois assim se consegue abarcar o conjunto de tecnologias ou setores que utilizam a escala nanométrica para a incorporação de propriedades inovadoras aos objetos fabricados. Em suma: quanto menor

${ }^{12}$ Hans-Georg Gadamer, Verdade e Método, Traços fundamentais de uma hermenêutica filosófica, 4. ed, [Tradução de Flávio Paulo Meurer], Petrópolis, Vozes, 2002, vol. I, pág. 448 e 452.

13 Peter Alexander Bleinroth Schulz, A encruzilhada da nanotecnologia: inovação, tecnologia $e$ riscos, Rio de Janeiro, Vieira \& Lent, 2009, pág. 49. 
a superfície, maior a quantidade de átomos nela encontrados. Com isso, se poderão fabricar produtos mais leves e resistentes, com menor quantidade de materiais e maiores potencialidades de uso. Destacam-se os seguintes setores: energia, agropecuária, tratamento e remediação de água, cerâmica e revestimentos, materiais compostos, plásticos e polímeros, cosméticos, aeroespacial, naval e automotivo, siderurgia, odontológico, têxtil, cimento e concreto, microeletrônica, diagnóstico e prevenção de doenças e sistemas de direcionamento de medicamentos. De acordo com Nelson Duran" ${ }^{14}$ " $\mathrm{Na}$ acepção moderna desta palavra, nano é um termo técnico usado em qualquer unidade de medida, significando um bilionésimo dessa unidade, por exemplo, um nanômetro equivale a um bilionésimo de um metro $(1 \mathrm{~nm}=1 / 1.000 .000 .000$ m) $[\ldots] . "$

Um nanômetro ( $\mathrm{nm}$ ) equivale a um bilionésimo de um metro (m), ou uma milionésima parte de um milímetro. Então, nanotecnologia refere-se a coisas extremamente pequenas, invisíveis ao olho nu e a quaisquer outros instrumentos, exceto aparelhos muito poderosos.

A nanotecnologia está baseada na manipulação átomos e moléculas para realizar processos, construir coisas ou construir seres vivos. Ela funciona re-arranjando a matéria na escala de átomos, que são a forma estrutural mais elementar de qualquer coisa ou de qualquer ser vivo. O domínio das nanotecnologias, como dito, encontra-se compreendido entre 0,1 e $100 \mathrm{~nm}$ (desde dimensões atômicas até aproximadamente o comprimento de onda da luz visível), região onde as propriedades dos materiais são determinadas e podem ser controladas.

Apesar da ciência dos átomos e moléculas simples, de um lado, e ciência da matéria, desde a micro até a macroestrutura, do outro, já estarem bem estabelecidas e fundamentadas, as nanotecnologias ainda se encontram na sua fase inicial, pois ainda há muito a ser compreendido sobre o comportamento dos materiais em nanoescala.

Vale alertar para o fato, na visão de riscos, de que "essas novas formas de materiais e de dispositivos serão precursores de uma idade revolucionária para a ciência e tecnologia contanto que possamos descobrir e utilizar [...]"15 da forma adequada, considerando-se todos os aspectos humanos e ambientais envolvidos. Nesse sentido vale destacar a colocação de Frank Quina ${ }^{16}$ :

${ }^{14}$ Nelson Duran, Luiz Henrique Capparelli Mattoso, Paulo Cezar de Morais. Nanotecnologia: introdução, preparação e caracterização de nanomateriais e exemplos de aplicação, São Paulo, Artliber Editora, 2006, pág. 19.

15 Ibid., pág. 20.

${ }^{16}$ Frank H. Quina, Nanotecnologia e o meio ambiente: perspectivas e riscos, Química Nova, São Paulo, v.27, n. 6, p.1028-29, 2004, Disponível em: <http://www.scielo.br/pdf/qn/v27n6/22297.pdf >. Acesso em: 28 jan. 2015. 


\begin{abstract}
Não obstante estas perspectivas animadoras dos benefícios da nanotecnologia para a melhoria do meio ambiente, não se deve subestimar o potencial para danos ao meio ambiente. As mesmas características que tornam as nanopartículas interessantes do ponto de vista de aplicação tecnológica, podem ser indesejáveis quando essas são liberadas ao meio ambiente. $\mathbf{O}$ pequeno tamanho das nanopartículas facilita sua difusão e transporte na atmosfera, em águas e em solos, ao passo que dificulta sua remoção por técnicas usuais de filtração. Pode facilitar também a entrada e o acúmulo de nanopartículas em células vivas. De modo geral, sabe-se muito pouco ou nada sobre a biodisponibilidade, biodegradabilidade e toxicidade de novos nanomateriais. A contaminação do meio ambiente por nanomateriais com grande área superficial, boa resistência mecânica e atividade catalítica pode resultar na concentração de compostos tóxicos na superfície das nanopartículas, com posterior transporte no meio ambiente ou acúmulo ao longo da cadeia alimentar; na adsorção de biomoléculas, com consequente interferência em processos biológicos in vivo; numa maior resistência à degradação (portanto, maior persistência no meio ambiente) e em catálise de reações químicas indesejáveis no meio ambiente (grifo nosso).
\end{abstract}

Por "seu caráter inter-multidisciplinar, o exemplo das Nanotecnologias introduz uma reflexão importante a respeito dos paradigmas a serem adotados em termos das interfaces e organização da pesquisa." ${ }^{17}$ Sabendo-se de todos os benefícios, implicações e possíveis impactos, alerta Wilson Engelmann ${ }^{18}$ :

o grande desafio que está ao lado dessa descoberta científica são os riscos que a mencionada manipulação poderá gerar para os seres humanos e o meio ambiente, pois as investigações científicas, no tocante à nanotoxicologia ainda são muito incipientes. No entanto, apesar disso, as pesquisas continuam e o consumo de produtos com partículas nanométricas já se encontram à disposição dos consumidores, especialmente por meio da internet. Não se sabe ainda os limites dessa investida humana, embora a natureza já tenha estabelecido os seus limites.

A partir dessa constatação "será necessária cautela e muita noção de limites e de ponderação, a fim de se criarem marcos regulatórios necessários e adequados à realidade brasileira, mas com os olhos focados também no contexto internacional"19 uma vez "que a humanidade pode simplesmente inviabilizar a sua permanência na Terra, por obra e desgraça, em larga escala, do seu estilo devorante. O alerta está acionado"20.

\footnotetext{
${ }^{17}$ Henrique E. Toma. Interfaces e organização da pesquisa no Brasil: da Química à Nanotecnologia, Química Nova, São Paulo, vol. 28, suppl., pág. S48-S51, 2005. Disponível em:< http://www.scielo.br/ pdf/qn/v28s0/26775.pdf>. Acesso em: 08 fev. 2015.

18 Wilson Engelmann, As Nanotecnologias e a Gestão Transdisciplinar da Inovação. [ Wilson (Org)], As Novas Tecnologias e os Direitos Humanos: Os Desafios e as Possibilidades para Construir uma Perspectiva Transdisciplinar, Paraná, Honoris Causa, 2011, pág. 299-00.

${ }^{19}$ Wilson Engelmann, André Stringhi Flores, André Rafael Weyermüller, Nanotecnologias, Marcos Regulatórios e Direito Ambiental, Curitiba, Honoris Causa, 2010, pág. 200.

${ }^{20}$ Juarez Freitas, Sustentabilidade: direito ao futuro. 1. ed., 1 ${ }^{\mathrm{a}}$. reimp., Belo Horizonte, Fórum, 2011, pág. 26.
} 
Mais uma vez, um "novo imperativo clama por outra coerência: não a do ato consigo mesmo, mas a dos seus efeitos finais para a continuidade da atividade humana no futuro." ${ }^{21}$ Conceito que atualmente se alarga para flexibilizar e incluir responsavelmente uma proteção ampla a todos os seres, humanos e não-humanos, respeitando e considerando direitos de igualdade e interesses semelhantes, ao que indica pelo menos no âmbito ideológico. Segundo Hans Jonas ${ }^{22}$ :

o horizonte relevante da responsabilidade é fornecido muito mais pelo futuro indeterminado do que pelo espaço contemporâneo da ação. Isso exige imperativos de outro tipo. Se a esfera do produzir invadiu o espaço do agir essencial, então a moralidade deve invadir a esfera do produzir, da qual ela se mantinha afastada anteriormente, e deve fazê-lo na forma de política pública. Nunca antes a política pública teve de lidar com questões de tal abrangência e que demandassem projeções temporais tão longas. De fato a natureza modificada do agir humano altera a natureza fundamental da política.

As pesquisas e aplicações das nanotecnologias estão num ritmo muitíssimo mais acelerado do que o conhecimento que se tem a respeito dela. Depara-se com a incerteza, o que nos remete a pensar em um espectro variado de situações não avaliadas seriamente, tais como a regulação específica sobre os limites da experimentações humanas e não-humanas, sobre os resíduos, gerenciamento e sua destinação final, além de um amplo debate presente na rotina da sociedade e dos grandes centros urbanos. A regulação deverá vir acompanhada da gestão dos riscos e do conhecimento do ciclo de vida dos nanomateriais, que são diferentes entre si.

Ou seja, o desenvolvimento é rápido em face das necessidades humanas, gera uma grande competição pelo domínio de novas tecnologias, contudo pouco se sabe ou se investiga sobre os impactos e efeitos a longo prazo, especialmente na forma que ela se desenvolve e é testada. Desafio a ser enfrentado, como destaca Nelson Duran ${ }^{23}$ :

O desenvolvimento da ciência em nanoescala encontra-se principalmente na fase pré-competitiva e espera-se que muitas aplicações de destaque nesse campo surjam nos próximos anos. A colaboração internacional em pesquisa fundamental, os desafios técnicos de longo prazo, a metrologia, educação e os estudos sobre as implicações societárias relatando os benefícios e/ ou danos que a nanotecnologia poderá trazer à sociedade e/ ou ao meio ambiente desempenharão um papel importante na afirmação e no seu crescimento (grifo nosso).

${ }^{21}$ Hans Jonas, O princípio da responsabilidade: ensaio de uma ética para a civilização tecnológica, [Hans Jonas; tradução do original alemão Marijane Lisboa, Luiz Barros Montez], Rio de Janeiro, Contraponto Ed. PUC-Rio, 2006, pág. 49.

22 Hans Jonas, O princípio da responsabilidade: ensaio de uma ética para a civilização tecnológica, [Hans Jonas; tradução do original alemão Marijane Lisboa, Luiz Barros Montez], Rio de Janeiro, Contraponto Ed. PUC-Rio, 2006, pág. 44.

${ }^{23}$ Nelson Duran, Luiz Henrique Capparelli Mattoso, Paulo Cezar de Morais, Nanotecnologia: introdução, preparação e caracterização de nanomateriais e exemplos de aplicação, São Paulo, Artliber Editora, 2006, pág. 25. 
Nesse debate, "o mesmo consumo que se presta a assegurar uma vida digna à população, acaba por, em um movimento inverso, afetar negativamente a qualidade de vida antes desejada". ${ }^{24}$ Cabe a sociedade questionar sobre as possíveis transformações sociais provocadas pela utilização irrestrita de nanotecnologias, bem como refletir sobre os riscos, impactos e segurança e sobre qual o engajamento público para regulamentação do uso, disposição e descarte dessa tecnologia, em especial sua experimentação toxicológica.

O meio adequado será a informação, educação e participação nesse processo. “É preciso pensar em soluções macro, que envolvam educação, conscientização, mudança de postura. Trata-se de verdadeira atuação preventiva". ${ }^{25}$ Isso só acontece por meio de processos informativos. A sociedade precisa o limite pelo qual são experimentadas, se respeitados princípios e questões éticas, humanas e não-humanas do seu surgimento até o consumo propriamente dito.

Será que se sabe qual é o custo para determinadas espécies, que são submetidas e subjugadas em nome de interesses egoístas, meramente ligados a satisfação e status pessoal, ao consumo propriamente dito, sempre obscurecido pelo discurso dos benefícios maiores à humanidade, como os ligados a saúde e bem-estar? Efetivamente devemos nos postar a uma reflexão maior e perguntar: realmente temos essa informação bem assimilada em nosso meio? Não somos apenas meio para um fim (lucro de grandes investidores, multinacionais e ou governos)? Não estamos retrocedendo às condutas que representam "em realidade, uma odiosa discriminação, da qual resulta lamentável inexecução do direito humano $[\ldots]$ '.. ${ }^{26}$

Tratando-se de nanotecnologias poucas são as fontes de informações sobre a sua classificação, principalmente sobre questões toxicológicas e fases de experimentação. Se existem, no mínimo deveriam ser melhor divulgadas, com maior área de penetração informativa e de debates acerca de suas implicações sociais. Imprescindível, portanto, a existência efetiva de um plano de gerenciamento da experimentação nanotecnológica, pois uma vez liberados no ambiente será praticamente impossível controlá-las.

Assim como a nanotecnologia, tantos outros, como por exemplo, os transgênicos, clonagem, mudanças climáticas, suscitaram incansáveis debates desenvolvidos em geral de modo insatisfatórios, já que "poucas vezes existe a preocupação em fornecer ao público desses debates as condições (informação, por exemplo) necessárias para construir o que deveria ser o objetivo da discussão: um consenso, um acordo firmado". ${ }^{27}$

\footnotetext{
${ }^{24}$ Patrícia Faga Iglecias Lemos, Resíduo sólido e responsabilidade civil pós-consumo, 2. ed. rev. e amp., São Paulo, Revista dos Tribunais, 2012, pág. 25.

25 Ibidem, pág. 35.

${ }^{26}$ José Nedel, Ética aplicada: Pontos e contrapontos, São Leopoldo, Editora Unisinos, 2004, pág. 19.

27 Peter Alexander Bleinroth Schulz, A encruzilhada da nanotecnologia: inovação, tecnologia e riscos, Rio de Janeiro, Vieira \& Lent, 2009, pág. 72.
} 
Mormente, neste momento, onde a tecnologia invade e cresce quase que imperceptivelmente aos olhos da humanidade, trazendo diversos benefícios e malefícios para a sociedade de consumo, deve os efeitos e reflexos da sua experimentação, aplicação e utilização ser debatidos incessantemente com a participação ativa da coletividade e do poder público.

Nesse período, "embora as nanotecnologias, pela sua grande gama de possibilidades, deem a impressão que o ser humano possa construir um novo mundo, há determinadas premissas básicas, muitas delas fornecidas pela experiência da história humana, que não poderão ser descuidadas". ${ }^{28}$

Uma delas reside no fato da ética e da experimentação (não) humana, de que forma se dará considerando a imensa necessidade de conclusões e pareceres efetivos, já que estamos diante de uma tecnologia de grande repercussão, contudo, com poucas informações conclusivas ou seguras de seu potencial efeito negativo para os seres nas mais variadas espécies experimentais. Ou seja, notória a necessidade gerada de uma significativa quantidade de experimentação a serem realizadas para obtermos um mínimo de certezas ou meios de controle de seus impactos. Nesse sentido demonstra a Agência Brasileira de Desenvolvimento Industrial ${ }^{29}$ :

\begin{abstract}
Um grande número de atividades tem sido realizado com o olhar voltado para os impactos da nanotecnologia sobre a saúde humana e o meio ambiente. Por se tratar de tecnologia emergente, a nanotecnologia ainda não tem um histórico importante relativamente a tais aspectos, o que determina a necessidade de estudos experimentais intensivos (grifo nosso).
\end{abstract}

Deve-se reconhecer com isso que o volume de experimentações deverão ser crescentes a medida que o assunto seja tratado no âmbito público, abertamente, em especial sobre questões toxicológicas, de modo que refletirá diretamente no uso de não-humanos na experimentação na busca dos potenciais efeitos oriundos das nanotecnologias, e portanto, atrelado a todo conhecimento e avanços, existem consequências, muitas provavelmente ligadas ao aumento expressivo do sofrimento de cobaias humanas ou não-humanas. Isso vem de encontro e reflete numa abordagem ética, em percepção evolutiva, na consideração de interesses não só humanos, mas planetárias. Nesse contexto há diversos envolvidos, e nesse contexto, a experimentação e o custo para outras espécies não-humanas, que sem a menor pretensão acabam subjugadas para atender os interesses exclusivos de uma lei de mercado e consumo humano.

\footnotetext{
${ }^{28}$ Wilson Engelmann. As Nanotecnologias e a Gestão Transdisciplinar da Inovação. [ Wilson (Org)], As Novas Tecnologias e os Direitos Humanos: Os Desafios e as Possibilidades para Construir uma Perspectiva Transdisciplinar, Paraná, Honoris Causa, 2011, pág. 308-9.

29 Agência Brasileira de Desenvolvimento Industrial (ABDI), Cartilha sobre nanotecnologia, Disponível em < http://www.abdi.com.br/Estudo/Cartilha\%20nanotecnologia.pdf $>$, Acesso em: 11 fev. 2015.
} 
Tudo está conectado, entretanto, o ser humano exerce um comportamento permissivo, voltado à satisfação de seus interesses individuais, e despreocupado, alheio às consequências a longo prazo, como se indefinidamente não repercutisse na sua esfera privada ou coletiva, seja nas presentes ou nas futuras gerações. Nesse sentido, professa José Nedel ${ }^{30}$ :

[...] o erro de infligir sofrimento a um ser não depende da espécie desse ser; o mesmo se pode afirmar do erro de matá-lo. A espécie a que pertencem [bebes deficientes] não é relevante para o seu status moral. O fato de ser membro da espécie homo sapiens não dá a um ser o direito a um tratamento melhor do que teria outro ser, com nível mental semelhante, que pertença a uma espécie diferente [...].

Não se sabe exatamente qual o impacto das nanopartículas na saúde humana e não-humana, tampouco no meio ambiente, o que remete novamente ao dever da prevenção, precaução, informação e educação, viabilizando o processo de participação da coletividade junto ao poder público nas discussões e definições sobre sua normatização. Ainda nesse contexto, importante ensinamento traz Peter Singer ${ }^{31}$ :

As pessoas às vezes pensam que as experiências com animais atendem a objetivos médicos vitais e podem ser justificadas com base no fato de que aliviam mais sofrimento do que provocam. Essa confortável crença não passe de um engano. Os laboratórios testam novos xampus e cosméticos que estão pretendendo comercializar pingando soluções concentradas desses produtos nos olhos de coelhos, num teste conhecido como 'teste de Draize'.

Vale lembrar que já existem diversos métodos alternativos, mas mesmo assim uma grande parcela das indústrias, incoerentemente, as maiores, que possivelmente teriam tecnologia e condições suficientes para utilizarem métodos alternativos não o fazem simplesmente porque "ideia de que o comportamento das pessoas é, em grande parte, produto das condições físicas e sociais nas quais elas vivem e se desenvolvem". 32 "[...] qualquer tecnologia per se não é nem boa nem má; entretanto, também nunca é neutra em termos socioeconômicos e seu caráter ou resultado dependerá do 'pacto social' que orientou seu desenvolvimento e uso." ${ }^{33}$ Segundo Tiago Fensterseifer ${ }^{34}$ :

\footnotetext{
${ }^{30}$ José Nedel, Ética aplicada: Pontos e contrapontos, São Leopoldo, Editora Unisinos, 2004, pág. 203.

${ }^{31}$ Peter Singer, Ética Prática, [Tradução Jefferson Luiz Camargo], 3. ed., São Paulo, Martins Fontes, 2002. pág. 75.

${ }^{32}$ Dale Jamieson, Ética e meio ambiente: uma introdução, São Paulo, Editora Senac São Paulo, 2010, pág. 17.

${ }^{33}$ Sônia Maria Dalcomuni, Inter-relações fundamentais para o desenvolvimento sustentável. [MARTINS, Paulo Roberto (org.)], Nanotecnologia, sociedade e meio ambiente, São Paulo, Xamã, 2006, pág. 63.

${ }^{34}$ Tiago Fensterseifer, Direitos fundamentais e proteção do ambiente: a dimensão ecológica da dignidade humana no marco jurídico constitucional do estado socioambiental de direito, Porto Alegre, Livraria do Advogado, 2008, pág. 58-9.
} 


\begin{abstract}
No passado, a ação humana, além de deter um poder limitado, tinha uma natureza temporal imediata ou presente (aqui e agora!), não repercutindo os seus efeitos e consequências para uma dimensão temporal futura. No entanto, hoje a relação de causa e consequência (ou efeito) vinculada à ação humana, principalmente no que tange a interações no ambiente, tem uma natureza acumulativa e projetada para o futuro. Muitas das ações humanas perpetradas hoje (como o uso de determinadas tecnologias) só poderão ser devidamente compreendidas com relação às suas possíveis consequências num momento futuro (grifo nosso).
\end{abstract}

Embora o ser humano tenha progredido sistematicamente no tratamento de questões culturais, certamente caminha ainda para uma longa e incansável busca até o amadurecimento de determinados temas que o cercam. Todo o avanço e desenvolvimento tecnológico contribuem de fato para o retroalimento da economia e desenvolvimento do país, de outra banda, também para a degradação do ser humano e não-humano, ignorando a existência de malefícios, relegando-os a suportar seus efeitos cumulativos em nome do progresso. $\mathrm{Ou}$ seja, "a vulnerabilidade da natureza provocada pela intervenção técnica do homem - uma vulnerabilidade que jamais fora pressentida antes que ela se desse a conhecer pelos danos já produzidos". ${ }^{35} \mathrm{O}$ mesmo ocorre atualmente com produtos nanotecnológicos, uma fase de novas descobertas em escalas atômicas.

Transitamos por um terreno totalmente novo, surpreendente, contudo desconhecido, onde os estudos sobre os impactos são quase inexistentes, sem qualquer resultado decisivo de investigações toxicológicas tendo em conta o uso e tratamento dessas nanopartículas em humanos e não-humanos.

Em grande parte, a preocupação do presente estudo se volta para as incertezas sobre os efeitos nanotoxicológico, em como são desenvolvidos os estudos sobre sua experimentação em animais humanos e não humanos, e quais são os desafios para a utilização do princípio da dignidade da pessoa humana como um fundamento ético para o desenvolvimento das nanotecnologias, já que os "surpreendentes avanços [...] impuseram uma nova ordem de reflexão sobre os direitos humanos. Agora, não apenas as desigualdades sociais, o poder político, econômico e cultural, mas, também, o próprio conhecimento científico tornou-se fonte de violação dos direitos humanos" ${ }^{36}$

Inúmeros benefícios são prometidos, sem, contudo, informar e dar publicidade sobre as implicações e potenciais riscos das nanotecnologias, ou seja, vivemos na era da tecnologia, da informação globalizada, no entanto, a sociedade consumidora permanece alheia aos processos decisórios, desinformada em relação ao que adquire e consome, sem um efetivo

${ }^{35}$ Hans Jonas, O principio da responsabilidade: ensaio de uma ética para a civilização tecnológica, [Hans Jonas; tradução do original alemão Marijane Lisboa, Luiz Barros Montez], Rio de Janeiro, Contraponto Ed. PUC-Rio, 2006, pág. 39.

${ }^{36}$ José Nedel, Ética aplicada: Pontos e contrapontos, São Leopoldo, Editora Unisinos, 2004, pág. 17. 
questionamento ou reflexão sobre a real necessidade ou utilidade, sobre um conhecimento participativo e responsável sobre o papel que exerce na condução e promoção dessa nova tecnologia, sobre os meios de experimentação e formas pelas quais são aprovadas, ou quais o custo humano ou não-humano diretamente ligados a satisfação de necessidades não tão explícitas.

A credibilidade de novas tecnologias resta abalada, considerado o seu potencial de risco no futuro. No caso das nanotecnologias, a necessidade de testes exaustivos remete ao mesmo conceito, um desafio para obtenção de certezas. Nessa avaliação, considerada a sua aplicação, deve ser examinado princípios como da dignidade da pessoa humana como fundamento ético para sua experimentação, aprovação, aplicação e consumo, ou seja, a qual preço? e de quem? A partir disso, deve-se buscar uma política pública para o controle e fiscalização, bases legais e normativas e meios adequados de conter os excessos.

Não obstante, as incertezas científicas exigirão uma consciência ética e comprometida com o seu impacto humano e não-humano, ou seja, não somente voltado para o lucro e desenvolvimento econômico. Os riscos caso se tornem realidade afetarão tanto os processos industriais, o meio ambiente e numa visão antropocêntrica o homem no topo da pirâmide, pois "o mau uso [...] pode levar a atos que causem danos à dignidade humana". ${ }^{37}$

No cenário as novas tecnologias, "há, assim, a configuração [...] de riscos inseridos em contexto de incertezas científicas (riscos abstratos) ou a impossibilidade de conhecimento e controle pelo sistema observador (perigos) [...] o que dificulta a aplicação de metodologias de quantificação de sua probabilidade". ${ }^{38}$ Dessa forma, a nova tecnologia representa de alguma forma um risco. Os efeitos de sua percepção são graduais e invisíveis aos sentidos humanos, podendo emergir somente nas futuras gerações.

Desse modo, toda manipulação em escalas invisíveis (nanos), enquadra-se como uma tecnologia que remete a todo cuidado na aplicação, monitoramento, avaliação e estudos de impacto e riscos. A complexidade das relações humanas proveniente do desenvolvimento da ciência e da tecnologia remete a movimentos e questionamentos sobre o ritmo e a consciência do avanço que a humanidade está inserida, sobre os efeitos futuros de nossas decisões. Com muita propriedade nos lembra Wilson Engelmann ${ }^{39}$ :

Sobretudo porque a tecnociência produz efeitos ambivalentes que se traduzem em benefícios e riscos. Ainda que esses riscos, o sejam em nome do progresso e do melhoramento do ser humano e da sociedade, não se pode ignorar a hipótese

\footnotetext{
37 Ibid., p. 17.

38 Délton Winter de Carvalho, Por uma necessária introdução ao direito dos desastres ambientai, Revista de Direito Ambiental, v. 67, p. 107-145, 2012.

39 Fernanda Frizzo Bragato, Os Direitos do Humano em Risco na Sociedade Tecnocientífica. [ENGELMANN, Wilson (Org)], As Novas Tecnologias e os Direitos Humanos: Os Desafios e as Possibilidades para Construir uma Perspectiva Transdisciplinar, Paraná, Honoris Causa, 2011, pág. 24. 
de que eles podem transformar em danos efetivos àqueles que visam em um primeiro momento beneficiar.

As tecnologias são estruturadas e empregadas nos produtos voltados ao consumo, visando o bem-estar da humanidade, muito embora intrinsecamente ligadas a atividades de natureza e produção de riscos "[...] inerentes à sociedade de risco [...] demarcados por sua invisibilidade, globalidade e imprevisibilidade. ${ }^{40}$ Ensina Carlos Machado de Freitas ${ }^{41}$ :

O termo risco surge com o próprio processo de constituição das sociedades contemporâneas, a partir do final do Renascimento e início das revoluções científicas, quando ocorreram intensas transformações sociais e culturais, associadas ao forte impulso nas ciências e nas técnicas, às grandes navegações e à ampliação e fortalecimento do poder político e econômico de uma nascente burguesa.

Por trás de todo avanço humano e tecnológico sempre estiveram presente os interesses coletivos e econômicos, sendo retroalimentado um pelo outro, gerando riscos localizados, na medida de impactos toleráveis e aceitáveis pela percepção ambiental e social. Nessa evolução, o conceito probabilístico de risco, somente adveio com a Revolução Industrial, até então todo desastre era caracterizado como manifestação dos Deuses. Sobre o tema, refere ainda, Carlos Machado de Freitas ${ }^{42}$ :

O processo de laicização das situações e eventos considerados perigosos e sua transformação em riscos, implicando na previsibilidade a partir da probabilidade, ocorreu de modo mais sistemático somente a partir da Revolução Industrial, estando relacionado à filosofia iluminista, ao fim das epidemias de pestes e à conversão da ciência e da tecnologia, enquanto eixos de poderosas transformações na sociedade e na natureza uma catástrofe, como castigo, e, da angústia de uma ameaça imaginária e sem objeto, foi lentamente sendo substituído.

Nesse processo, através do desenvolvimento científico e tecnológico e das consequentes transformações na sociedade, na natureza e na própria característica e dinâmica das situações e eventos perigosos, o homem passa a ser responsável pela geração e remediação de seus próprios males.

${ }^{40}$ Délton Winter de Carvalho, Dano ambiental futuro: a responsabilização civil pelo risco ambiental, Rio de Janeiro, Forense Universitária, 2008, pág. 59.

${ }^{41}$ Carlos Machado de Freitas, Avaliação de Riscos dos Transgênicos Orientada pelo Princípio da Precaução. [TELlES, José Luiz; VALLE, Silvio (orgs.)], Bioética e biorisco: abordagem transdisciplinar, Rio de Janeiro, Interciência, 2003, pág. 114.

${ }^{42}$ Carlos Machado de Freitas, Avaliação de Riscos dos Transgênicos Orientada pelo Princípio da Precaução. [TELlES, José Luiz; VALlE, Silvio (orgs.)], Bioética e biorisco: abordagem transdisciplinar, Rio de Janeiro, Interciência, 2003, pág. 115. 
O conceito de risco, tal como é predominantemente compreendido na atualidade, resulta desse processo, cabendo ao próprio homem a atribuição de desenvolver, através de metodologias baseadas nas ciências e tecnologia, a capacidade de interpretá-los e analisar, para melhor controlá-los e remediar. Conforme já visto, a evolução científica e tecnológica crescente traz consigo uma enorme gama de preocupações e reflexões a serem feitas sobre os seus efeitos nocivos ao meio ambiente.

As novas tecnologias estão sendo utilizadas em diversas atividades e produtos para alavancar o desenvolvimento econômico e social de países, considerando-se que é o preço que a sociedade deve pagar pelo progresso material. Além disso, "os riscos ecológicos gerados pelas novas tecnologias tratam-se, na maioria das vezes, de riscos abstratos, e seu contexto de incerteza cientifica tem grande conexão com a principal característica dos problemas ecológicos, ou seja, a complexidade." ${ }^{43}$

O uso de novas tecnologias sempre esteve associado ao desenvolvimento econômico bem como ao risco. Vale lembrar que desde o início dos anos 80 houve um rico processo de transformação política e institucional reavivando uma nova conscientização ambiental, diga-se de passagem, estimulada pela ocorrência de vários acidentes ecológicos de impacto e repercussão internacional, como os experimentados em Bopal, na Índia e Chernobyl, na União Soviética, além da constante preocupação com o efeito estufa, mudança climática, chuva ácida, dentre tantas outras que nos fazem parar e pensar sobre os motivos, causas e efeitos da aplicação da nova ciência e tecnologia, nem sempre pró homem e meio ambiente. Como bem ensejado por Sônia Maria Dalcomuni ${ }^{44}$ :

combinação de demandas com muitas outras políticas de modo a promover um efeito abrangente em toda a estrutura de produção e consumo na sociedade. Isso requer uma abordagem mais sistêmica para a definição de políticas. Assim, mesmo considerando-se apenas o desenvolvimento sustentável em sentido estrito, a escolha de quais opções de políticas usar depende menos de sua força ou fraqueza teórica e sim da habilidade de construir um consenso social para a adoção de opções específicas, o que abre espaço para a busca de construção de uma nova ética para o desenvolvimento, com preconizamos. Desafio que se amplifica de forma sem precedentes se incluímos um novo conceito de natureza, além de democracia, respeito à diversidade e preocupações quanto à especialização das atividades humanas.

\footnotetext{
${ }^{43}$ Délton Winter de Carvalho, Dano ambiental futuro: a responsabilização civil pelo risco ambiental, Rio de Janeiro, Forense Universitária, 2008, pág. 68.

${ }^{44}$ Paulo Roberto Martins, Nanotecnologia, sociedade e meio ambiente, São Paulo, Xamã, 2006, pág. 62 .
}

Araucaria. Revista Iberoamericana de Filosofía, Política y Humanidades, año 17, n⿳0 33. Primer semestre de 2015. Pp. 151-181. ISSN 1575-6823 e-ISSN 2340-2199 doi: 10.12795/araucaria.2015.i33.07 
Reforça-se já que, "os riscos inerentes à forma pós-industrial da sociedade, dentre os quais se destacam os ambientais, são "marcados por sua (1) indivisibilidade; (2) globalidade; e (3) transtemporalidade." 45 . Situação que reforça a necessidade e intensificação do diálogo entre os atores do atual cenário nanotecnológico, principalmente sobre os efeitos retardados da absorção de resíduos que contaminam invisivelmente o meio ambiente e o ser humano.

Atualmente adquirimos, consumimos e descartamos com o tempo uma enorme gama de produtos, muitos desses prometendo grandes avanços e melhorias de qualidade em razão do uso de novíssimas tecnologias aplicadas. No entanto, o que não sabemos ou temos consciência, devido à falta de informações, é que devido "a invisibilidade dos riscos e a dificuldade da avaliação científica"46, vivemos constantemente como verdadeiras cobaias, submissas ao nosso próprio desejo de progresso e consumo de novas tecnologias, contudo, sem refletirmos que essa busca se realiza "por meio da aplicação do código provável/improvável" ${ }^{47}$ de riscos futuros, colocando-se por vezes, em segundo plano a devida precaução.

"Existem muitas teorias acerca das causas dos problemas ambientais. Talvez a mais importante hoje em dia se baseiem em falhas e soluções tecnológicas. Essa concepção afirma que somos vítimas de nosso sucesso."48 Devemos, portanto, lembrar que nossas ações têm efeitos e consequências, quando mais potencializadas pela permissividade tecnológica sem precaução, pois se tratando do meio ambiente, os riscos e resultados das novas tecnologias "tem a capacidade de atingir um número indeterminado de sujeitos, naquilo que a dogmática jurídica denomina interesses transindividuais (difusos e coletivos)." ${ }^{49}$

Conforme se verificou, os riscos são inerentes às atividades exploradoras e respondem objetivamente por eventuais danos causados ao meio ambiente. Diante disso, restam evidente as "necessidades de desenvolvimento de abordagens analíticas e de instrumentos e intervenção econômica para impulsionar os processos de inovação para o desenvolvimento sustentável em sua acepção ampla." 50 Do contrário, estaremos permitindo o progresso da degradação ambiental em níveis talvez irreversíveis já que estaremos de olhos vendados frente a possíveis e muito prováveis efeitos nocivos, nos mais diversos aspectos, às sociedades contemporâneas e futuras.

\footnotetext{
${ }^{45}$ Délton Winter de Carvalho, Dano ambiental futuro: a responsabilização civil pelo risco ambiental, Rio de Janeiro, Forense Universitária, 2008, pág. 67.

46 Ibid., pág. 67.

47 Ibid., pág. 67.

48 Dale Jamieson, Ética e meio ambiente: uma introdução, [Dale Jamieson; tradução de André Luiz de Alvarenga], São Paulo, Editora Senac São Paulo, 2010, pág. 34.

${ }^{49}$ Délton Winter de Carvalho, Dano ambiental futuro: a responsabilização civil pelo risco ambiental, Rio de Janeiro, Forense Universitária, 2008, pág. 68.

50 Paulo Roberto Martins, Nanotecnologia, sociedade e meio ambiente, São Paulo, Xamã, 2006, pág. 49
}

Araucaria. Revista Iberoamericana de Filosofía, Política y Humanidades, año 17, $\mathrm{n}^{\circ}$ 33. Primer semestre de 2015. Pp. 151-181. ISSN 1575-6823 e-ISSN 2340-2199 doi: 10.12795/araucaria.2015.i33.07 
Portanto, "o risco decorre sempre de uma tomada de decisão, consistindo em elemento interno ao sistema". ${ }^{51}$ "Diante das situações de risco previstas na Constituição, o Poder Público e a coletividade têm o dever de exigir medidas eficazes e rápidas na manutenção de toda forma de vida, não só humana." 52 Além de construir uma nova cultura onde o homem "é apenas mais um elemento integrante da natureza e que em sua preservação e melhoria residem às bases de nossa qualidade de vida." ${ }^{53}$ Conforme afirma Martins ${ }^{54}$ :

Embora o termo risco tenha suas origens identificadas no século XVII, foram necessários três séculos para que ocorressem importantes transformações que contribuíram para o surgimento da avaliação e do gerenciamento de riscos, enquanto procedimento científicos institucionalizados, como parte do modo contemporâneo de pensar e enfrentar os perigos. Esses procedimentos surgiram em um determinado período histórico, como resposta técnica a problemas simultaneamente sociais.

Portanto, já se vislumbra que a reflexão sobre a importância da análise de sustentabilidade dos efeitos no meio ambiente do descarte de resíduos nanotecnológicos, uma vez que a frequência e a exposição não são equânimes, sendo os riscos muito maiores. Em conformidade com os riscos de exposição, é crescente o debate humanista acerca da responsabilidade moral e ética da aplicação industrial e dos efeitos da nanotecnologia (partículas nanos). Nesse sentido, sinaliza Esper A. Cavalheiro ${ }^{55}$ :

Dentre as questões morais e éticas relacionadas à aplicação da nova Convergência Tecnológica destacam-se as preocupações quanto às relações entre o humano e a natureza, entre o corpo, a mente e o "espírito"; à existência e o caráter do livre-arbítrio e seu impacto sobre os conceitos de responsabilidade moral e legal e à delegação dessas mesmas responsabilidades a artefatos tecnológicos; ao relacionamento entre entidades vivas e não-vivas; à manipulação do código genético e suas consequências, entre outras.

Contudo, apesar do progressivo debate entre especialistas, o assunto ainda não chegou ao amplo conhecimento do público, que nesse caso deixa-se levar

\footnotetext{
${ }^{51}$ Délton Winter de Carvalho, Dano ambiental futuro: a responsabilização civil pelo risco ambiental, Rio de Janeiro, Forense Universitária, 2008, pág. 70.

${ }_{52}$ Paulo Affonso Leme Machado, Direito ambiental brasileiro, 18. ed., rev. atual. e ampl., São Paulo, Malheiros, 2010, pág. 144.

${ }_{53}$ Paulo Roberto Martins, Nanotecnologia, sociedade e meio ambiente, São Paulo, Xamã, 2006, pág. 53.

${ }^{54}$ Carlos Machado de Freitas, Avaliação de Riscos dos Transgênicos Orientada pelo Princípio da Precaução. [TELLES, José Luiz; VALLE, Silvio (orgs.)], Bioética e biorisco: abordagem transdisciplinar, Rio de Janeiro, Interciência, 2003, pág. 115.

${ }^{55}$ Esper A. Cavalheiro, A nova convergência da ciência e da tecnologia, Novos estudos - CEBRAP, n.78, pág. 23-30, 2007, Disponível em: <http://www.scielo.br/pdf/nec/n78/04.pdf>. Acesso em: 28 jan. 2015 .
} 
pela publicidade de alegados benefícios, sem exigir qualquer investigação prévia e clara de seus efeitos sobre o solo, a água, o ar e a saúde humana, portanto, presumindo-se inofensivos à saúde e ao meio ambiente. Em idêntico sentido é o abalizado magistério de Wilson Engelmann ${ }^{56}$ : "o risco da utilização do produto ou serviço ainda não foi confirmado pela Ciência. É aquele risco para a integridade e saúde do consumidor que não é considerado certo, em face da incerteza científica. Com efeito, é nesta situação de risco que a precaução reside, ou seja, um risco de dano irreversível futuro."

Confirma-se, portanto, que o alto grau de obsolescência e rápido avanço tecnológico condicionam o consumo e o volume de lixo produzido sem qualquer preocupação com resultados de sustentabilidade. Ou seja, a toda evidencia, surge a preocupação com a disposição final, visto que o descarte de resíduos representa um potencial impacto ambiental. Nessa tomada de consciência prevalece a necessidade de informação adequada no consumo de novas tecnologias. O desafio atual é superar a dificuldade e inexistência de métodos e instrumentos adequados para diagnosticar, tratar e prevenir os efeitos nocivos e adversos das partículas nanos. Vislumbra-se que "a partir de uma comunicação de risco pode haver uma racionalização das incertezas em detrimento de um medo irracional e paralisante atinente aos riscos tecnológicos, aos perigos naturais e aos riscos híbridos". ${ }^{57}$ Com propriedade observa Wilson Engelmann ${ }^{58}$ :

\section{Observa-se que a efetivação da precaução dar-se-á através do direito básico e fundamental do consumidor à informação, corolário dos princípios da transparência e da boa-fé (art. $4^{\circ}, \mathrm{CDC}$ ), reitores do ordenamento consumerista. Conseguintemente, frente a um produto e serviço que ofereça nocividade ou periculosidade em potencial, o legislador traz um dever de informação diferente daquele consignado no rol dos direitos fundamentais do consumidor (art. $6^{\circ}, \mathrm{CDC}$ ), mais ampliado em face da potencialidade de risco (grifo nosso).}

Por esse motivo, urgem medidas regulatórias visando nortear o futuro das pesquisas e investimentos públicos ou privados e todas suas implicações, bem como regulamentar os meios de informação e consumo dessas novas tecnologias, face à "vulnerabilidade técnica dos consumidores dos produtos concebidos a partir de nanotechs [...]". ${ }^{59}$ Inexiste essencialmente "o dever de informação ostensiva e adequada [...] expressamente consignado no produto

\footnotetext{
${ }^{56}$ Wilson Engelmann, André Stringhi Flores, André Rafael Weyermüller, Nanotecnologias, Marcos Regulatórios e Direito Ambiental, Curitiba, Honoris Causa, 2010, pág. 196.

${ }^{57}$ Délton Winter de Carvalho, Por uma necessária introdução ao direito dos desastres ambientais, Revista de Direito Ambiental, v. 67, pág. 107-145, 2012.

58 Wilson Engelmann, André Stringhi Flores, André Rafael Weyermüller, Nanotecnologias, Marcos Regulatórios e Direito Ambiental, Curitiba, Honoris Causa, 2010, pág. 196.

59 Ibid., p. 191.
} 
ou serviço"60 (rotulagem), permitindo "[...] ao consumidor o conhecimento específico das propriedades, dos malefícios e das consequências advindas da utilização de novos produtos" "61, dentre outros meios de proteção, fato atualmente desconsiderado pelo ordenamento jurídico. Nesse sentido, atesta ainda Wilson Engelmann ${ }^{62}$ :

as pesquisas desenvolvidas em nano escala projetam-se como uma verdadeira Revolução Científica, pois estão sendo visitados espaços nunca antes percorridos, embora já existentes desde sempre na natureza. Por isto, quanto menores forem as escalas das pesquisas, mais poderosos serão os resultados. Como decorrência, maiores serão os riscos que estas atividades estarão produzindo (grifo nosso).

Nesse caso, consideradas as probabilidades tanto da exposição, manuseio, disposição e descarte de produtos nanotecnológicos, sejam pelo consumidor final ou pela cadeia produtiva, especialmente as pessoas que para produzir necessariamente devem manter o contato direto com produtos tecnológicos, e, considerando o desconhecimento dos seus efeitos na saúde e no meio ambiente, relevante se torna o dever de informação, educação, participação e políticas públicas voltadas ao incentivo, instrução e formação para preservação da saúde humana e do meio ambiente, visando a sustentabilidade social-políticaeconômica. Afirmativa corroborada por Wilson Engelmann ${ }^{63}$ :

Faz-se necessária uma atitude antecipadora a esses riscos através de práticas e políticas do Estados nacionais, como leis e mecanismos de controle, bem como supranacionais, que possam comunicar ações preventivas em face dos danos que a humanidade pode produzir, os quais podem ser irreversíveis, tais como as consequências de aplicação sem controle de tecnologias como a nuclear e genética quando inseridas no contexto das nanotecnologias.

Diante tamanha evolução e presunção de benefícios apontados pelos trabalhos científicos e tecnológicos desenvolvidos nas últimas décadas, tornase inquestionáveis a necessidade de haver informação e no "apoio crescente ao desenvolvimento de pesquisas em nanotoxicologia e na regulamentação de nanoprodutos". ${ }^{64}$ No entanto, surgem argumentos contrários baseados nas dificuldades de obtenção de resultados. Sobre essa problemática, considera Peter Schulz ${ }^{65}$ :

\footnotetext{
${ }^{60}$ Ibid., p. 197.

${ }^{61}$ Ibid., p. 191.

${ }^{62}$ Ibid., p. 171.

${ }^{63}$ Wilson Engelmann, André Stringhi Flores, André Rafael Weyermüller, Nanotecnologias, Marcos Regulatórios e Direito Ambiental, Curitiba, Honoris Causa, 2010, pág.145.

${ }^{64}$ Peter Alexander Bleinroth Schulz, A encruzilhada da nanotecnologia: inovação, tecnologia e riscos, Rio de Janeiro, Vieira \& Lent, 2009, pág. 96.

${ }^{65}$ Ibid., pág. 101.
} 
provavelmente milhares de novos materiais sendo pesquisados, os responsáveis pela regulamentação de saúde e de segurança têm dificuldades para manter o passo na detecção de riscos. Do ponto de vista técnico, estudos toxicológicos tradicionais, que testam um material de cada vez, parecem ser inadequados para separar o benigno do prejudicial. Para se ter uma ideia da dimensão do desafio dessa primeira década do século XXI, o número de produtos de nanotecnologia listado em março de 2006 totalizava um pouco mais de 200. Em março de 2007 já eram mais de 400 e um ano depois mais de 600 (grifo nosso).

A toda evidencia, qualquer justificativa caracteriza uma ruptura aos princípios básicos da prevenção e precaução, pilares de todo e qualquer desenvolvimento. Reforçando essa ideia, considera Carlos Machado de Freitas ${ }^{66}$ :

\begin{abstract}
Se por um lado, os avanços científicos e tecnológicos contribuíram para a redução da prevalência de determinadas doenças infecto-contagiosas, por outro, contribuíram para o surgimento e aumento de 'novos riscos', de origem tecnológica, envolvendo agentes radioativos, químicos e biológicos [...] Foi somente a partir dos anos 1970, quando se fortaleceram os movimentos sociais que lutavam pelas questões ambientais e melhoria da qualidade de vida, em paralelo com uma maior cobertura da imprensa, possibilitada em parte pelas massificação dos meios de comunicação, que se intensificou a publicização dos debates sobre as ameaças relacionadas aos produtos e processos industriais perigosos. As permanentes discordâncias entre os especialistas, acerca das consequências de muitos desses produtos e processos para a saúde dos trabalhadores e das populações expostas, para o meio ambiente e as gerações futuras, não só passaram a revelar os limites e as incertezas do conhecimento científico sobre os diferentes problemas, como também trouxeram inúmeros outros atores não especialistas (ONG's, sindicatos, associações de moradores, grupos de interesse, etc.) para o centro do debate, contribuindo para uma mudança no status social dos riscos (grifo nosso).
\end{abstract}

Nessa asserção, os riscos da tecnologia avançam mais rápido do que a percepção de responsabilidade moral e ética da sociedade, capaz de sopesar questões de segurança e benefícios. Os produtos oriundos das nanotecnologias, portanto, estão sendo comercializados em produtos como farmacêuticos, cosméticos, eletrônicos, petroquímico, agroindustrial, entre outros. Não se restringem a esta lista, sendo desenvolvidos para um amplo leque de aplicações, "todos têm em comum o fato de exporem os riscos a que a criatividade humana e o poder da ciência expõem a humanidade." ${ }^{\prime 27}$

${ }^{66}$ Carlos Machado de Freitas, Avaliação de Riscos dos Transgênicos Orientada pelo Princípio da Precaução, [TELlES, José Luiz; VALLE, Silvio (orgs.)], Bioética e biorisco: abordagem transdisciplinar, Rio de Janeiro, Interciência, 2003, pág. 116.

${ }^{67}$ Fernanda Frizzo Bragato, Os Direitos do Humano em Risco na Sociedade Tecnocientífica. [ENGELMANN, Wilson (Org)], As Novas Tecnologias e os Direitos Humanos: Os Desafios e as Possibilidades para Construir uma Perspectiva Transdisciplinar, Paraná, Honoris Causa, 2011, pág. 23. 
A sociedade ainda não saiu da sua zona de conforto, sobretudo para buscar informação e participação nesse processo de amadurecimento e desenvolvimento tecnológico, eis que permanece inerte e alheio ao "potencial benéfico ou não das recentes técnicas", ${ }^{68}$ sem deter maiores informações dos efeitos à saúde e ao meio ambiente. Nesse contexto, merece novamente destaque o posicionamento de Carlos Machado de Freitas ${ }^{69}$ :

para que avaliações de risco à saúde sejam realizadas, sem a necessidade de novas e substantivas pesquisas, torna-se vital que existam informações detalhadas acerca das vias de exposições, estimativas da população exposta e dos efeitos a saúde, associados com a exposição na forma da relação doseresposta.

Sabe-se que a sede de desenvolvimento envolve e cobre a visão, que permanece entorpecida pelos benefícios da tecnologia imediatista. Nesse ritmo, subtrai-se muitas vezes, em nome do progresso e da sedução do mercado tecnológico, etapas de prevenção e precaução. Estudos científicos e técnicos são direcionados ao desenvolvimento de uma nova tecnologia, mas não simultaneamente aos seus efeitos produzidos na saúde humana e no meio ambiente. Tais pesquisas são relevadas a constatação direta, por meio da observação, ou seja, suspensas até que, a longo prazo, os seus efeitos demonstrem se era ou não prejudicial e irreversível para o meio ambiente.

A avaliação de riscos, mais do que uma resposta técnica às preocupações coletivas, converteu-se também numa determinada resposta política à formação de consenso nos processos decisórios. ${ }^{70}$ Essencial, portanto, já que "a aventura da tecnologia impõe, com seus riscos extremos, o risco da reflexão extrema" ${ }^{71}$ Merece ser trazido à baila o pensamento de Hans Jonas ${ }^{72}$ :

A presença do homem no mundo era um dado primário e indiscutível de onde partia toda ideia de dever referente à conduta humana: agora, ela própria tornou-se um objeto de dever - isto é, o dever de proteger a premissa básica de todo o dever, ou seja, precisamente a presença de meros candidatos a um universo moral no mundo físico do futuro; isso significa, entre outras coisas, conservar este mundo físico de modo que as condições para uma tal presença permaneçam intactas; e isso significa proteger a sua vulnerabilidade diante de uma ameaça dessas condições.

\footnotetext{
${ }^{68}$ Ibid., pág. 23.

${ }^{69}$ Carlos Machado de Freitas, Avaliação de Riscos dos Transgênicos Orientada pelo Princípio da Precaução. [TELlES, José Luiz; VALlE, Silvio (orgs.)], Bioética e biorisco: abordagem transdisciplinar, Rio de Janeiro, Interciência, 2003, pág. 120.

70 Ibid., pág. 120.

${ }^{71}$ Hans Jonas, O princípio da responsabilidade: ensaio de uma ética para a civilização tecnológica, [Hans Jonas; tradução do original alemão Marijane Lisboa, Luiz Barros Montez], Rio de Janeiro, Contraponto Ed. PUC-Rio, 2006, pág. 22.

${ }^{72}$ Ibid., pág. 45.
} 
É, portanto dever do poder público observar como parâmetro mínimo de direito fundamental a saúde, o que resta assegurado pelo art. 196 da Constituição Federal ${ }^{73}$ : Art. 196. A saúde é direito de todos e dever do Estado, garantido mediante políticas sociais e econômicas que visem à redução do risco de doença e de outros agravos e ao acesso universal e igualitário às ações e serviços para sua promoção, proteção e recuperação. (grifo nosso).

Conclui-se a partir dessa interpretação que, considerando-se o direito a atividade humana digna e a saúde com qualidade de vida e equilíbrio ambiental, que todo e qualquer meio alternativo de subsídios para uma boa gestão ambiental deve levar em consideração os instrumentos e as ferramentas que a própria legislação alcança aos empreendimentos potencialmente ou efetivamente poluidores para se adequarem à nova realidade.

\section{Como desenvolver marcos regulatórios neste cenário de incertezas?}

O crescente avanço da ciência e da tecnologia, em especial as pesquisas voltadas para a escala "nano", trouxe consigo o debate sobre os possíveis riscos, presentes e futuros, para a humanidade e para o meio ambiente, oriundos de sua utilização e descarte invisível. Conforme assevera $\mathrm{Nedel}^{74}$ :

[...] o preocupante é que a humanidade, ainda a meio caminho da conquista dos direitos humanos no plano social e político, vê-se coagida a defender-se das ameaças oriundas da ciência e da medicina, áreas nas quais, por tradição, a humanidade punha suas esperanças, no plano das melhorias de bem-estar e saúde, e as tinha como insuspeitáveis aliadas na luta pelos direitos humanos (grifo nosso).

"O Brasil, por exemplo, não possui em seu ordenamento jurídico uma lei que trate das nanotecnologias. Não se tem como controlar sua produção, comercialização e utilização". ${ }^{75} \mathrm{E}$ nesse caso, "não se pensa em proibir, mas regular tendo como orientação o respeito ao ser humano e à natureza". ${ }^{76}$ Isso traz ao debate as formas de regulação e normatização do uso e em especial da experimentação humana e não-humana das nanotecnologias, "na perspectiva de assegurar à sociedade que

\footnotetext{
${ }^{73}$ BRASIL, Constituição (1988), Constituição da República Federativa do Brasil de 1988. Brasília, DF, 5 de outubro 1988, Disponível em: < http://www.planalto.gov.br/ccivil_03/constituicao/constitui\% C3\%A7ao.htm>. - Acesso em 13 fev. 2015.

74 José Nedel, Ética aplicada: Pontos e contrapontos, São Leopoldo, Editora Unisinos, 2004, pág. 18.

${ }^{75}$ Wilson Engelmann, André Stringhi Flores, André Rafael Weyermüller, Nanotecnologias, Marcos Regulatórios e Direito Ambiental, Curitiba, Honoris Causa, 2010, pág. 168.

${ }_{76}$ Wilson Engelmann, As nanotecnologias e suas interações com o Meio Ambiente: dos riscos aos tópicos associados ao nanoambiente. VI Simpósio Dano Ambiental na Sociedade de Risco, 2011, Florianópolis, Anais do VI Simpósio Dano Ambiental na Sociedade de Risco, Florianópolis, FUNJAB, 2011, v. 1CD, pág. 998-1024.
} 
seu desenvolvimento industrial seja conduzido no futuro segundo um marco seguro, responsável e sustentável". ${ }^{77}$ As nanotecnologias são consideradas o motor propulsor da próxima revolução industrial e tem um potencial imenso de transformar profundamente as relações sociais, econômicas e políticas, bem como as relações das pessoas com o meio ambiente, ainda que presente seu estado de incerteza sobre seus efeitos futuros. Surge daí a necessidade de um comprometimento com normas reguladoras e éticas, demonstrando a relevância de um sistema jurídico seguro e ágil para o tratamento das incertezas, indeterminações e gravidade dos fenômenos dos desastres. É necessário contar com ambientes regulatórios e institucionais favoráveis às transformações produtivas e aos investimentos em inovação. Para tanto, abre-se o espaço para a inovação no/do Direito, fomentando o movimento do chamado diálogo entre as fontes do Direito. As nanotecnologias trazem desafios e necessidades que não podem aguardar o desenvolvimento do processo seletivo, com um conjunto de etapas que o deixa naturalmente moroso e inadequado a sua renovação e flexibilização à medida em que surgem as novidades e as mudanças geradas a partir da escala nanométrica.

A toda busca surge dúvidas e preocupações marcantes sobre dados quantitativos e qualitativos de testes e métodos desenvolvidos, tanto de criação como de experimentação, visando obter resultados de avaliação de riscos do ciclo de vida das nanotecnologias. Frente aos inúmeros questionamentos, evidencia-se em contrapartida, pouca atividade e investimentos destinados à pesquisa sobre aspectos éticos, ambientais e inerentes à saúde e à segurança em particular, ao longo de todo o ciclo de vida das aplicações científicas, humanas e não-humanas. Conforme destaca Wilson Engelmann ${ }^{78}$ :

\begin{abstract}
Nenhuma área do conhecimento está imune às transformações que advirão dos avanços das pesquisas com as nanotecnologias. No Direito, em particular, a fim de se integrar na construção transdisciplinar do conhecimento, impulsionado pelo trabalho realizado nas ciências duras, serão necessários ajustes na sua estrutura das fontes. Será preciso dar conta da insegurança e da imprevisibilidade destes novos tempos, características que estão substituindo a segurança e a previsibilidade próprias do modo positivista (especialmente o legalista) de conceber o Direito (grifo nosso).
\end{abstract}

O princípio da dignidade da pessoa humana surge como um marco regulatório, aliada aos princípios internacionais compromissados com o bem estar coletivo. Segundo Hans Jonas ${ }^{79}$ :

\footnotetext{
77 Agência Brasileira de Desenvolvimento Industrial(ABDI), Panorama de Nanotecnologia, Disponível em: <ww.abdi.com.br/Estudo/Panorama\%20de\%20Nanotecnologia.pdf>, Acesso em: 11 de fev. 2015.

78 Wilson Engelmann, André Stringhi Flores, André Rafael Weyermüller, Nanotecnologias, Marcos Regulatórios e Direito Ambiental, Curitiba, Honoris Causa, 2010, pág. 205.

${ }^{79}$ Hans Jonas, O princípio da responsabilidade: ensaio de uma ética para a civilização tecnológica, [Hans Jonas; tradução do original alemão Marijane Lisboa, Luiz Barros Montez], Rio de Janeiro, Contraponto Ed. PUC-Rio, 2006, pág. 53.
} 
Sem dúvida, louva-se o legislador também pela durabilidade de sua criação, mas não por planejar previamente algo que só deve tornar-se realidade para os pósteros, sendo inalcançável para os contemporâneos. Seu esforço consiste em criar uma estrutura política viável, e a prova da viabilidade está na duração, a mais inalterada possível, do que foi criado. O melhor Estado, assim se imaginava, é também o melhor para o futuro, pois o seu equilíbrio interno atual garante o futuro; evidentemente, ele será também o melhor Estado no futuro, pois os critérios de uma boa ordem (entre os quais o da durabilidade) não se modificam, já que a natureza humana não se modifica. As imperfeições dessa natureza devem estar incluídas na concepção de uma ordem política viável, feita pelo legislador sábio. Por isso, o legislador não propõe o Estado perfeito em termos ideais, mas o melhor em termos reais, isto é, o melhor Estado possível, tão somente e tão ameaçado hoje quanto o será no futuro (grifo nosso).

Nessa linha são conduzidos os temas, as reflexões e as posturas para com o futuro, na tentativa de romper e minimizar os riscos, para tanto, calcados em bases sólidas, éticas e principiológicas. Assim, com propriedade afirma Fernanda Frizzo Bragato ${ }^{80}$ : “é por isso que, apesar das dificuldades teóricas, temse avançado no sentido de impor limites ético-jurídicos à ação tecnocientífica quando esta conflita com os direitos humanos ou coloca em risco o próprio destina das futuras gerações e da humanidade como um todo".

Surge a demanda de programas regulatórios nas áreas de propriedade industrial, de metrologia e normatização científica e de regulação na experimentação (não) humana, todas focadas na consideração de iguais interesses. Para Wilson Engelmann ${ }^{81}$ :

A insegurança e a imprevisibilidade não residem apenas na circunstância da multiplicidade de textos legais que abalaram a estrutura codificada, mas, fundamentalmente, na impossibilidade de manter-se, no mundo em que se vive, a integridade lógica do sistema. A globalização se mostra como um desafio complexo, em que o sistema tradicional não dá mais conta das novas demandas sociais. Este obstáculo será incrementado a partir do momento em que demandas envolvendo as nanotecnologias começarem a exigir respostas jurídicas (grifo nosso).

Diante essa previsão e numa ótica do desconhecido e das incertezas, como é o caso das nanotecnologias, somadas ao fato dos seus riscos invisíveis aos olhos humanos em algum momento pós-consumo, deve-se pautar pela aplicação dos princípios da dignidade da pessoa humana bem como urge maior incidência

${ }^{80}$ Fernanda Frizzo Bragato, Os Direitos do Humano em Risco na Sociedade Tecnocientífica. [ENGELMANN, Wilson (Org)], As Novas Tecnologias e os Direitos Humanos: Os Desafios e as Possibilidades para Construir uma Perspectiva Transdisciplinar, Paraná, Honoris Causa, 2011, pág. 27.

81 Wilson Engelmann, André Stringhi Flores, André Rafael Weyermüller, Nanotecnologias, Marcos Regulatórios e Direito Ambiental, Curitiba, Honoris Causa, 2010, pág. 205. 
da informação, como meios adequados e necessários a experimentação e sustentabilidade.

Portanto, para atingir o desafio dos marcos regulatório, será necessário implementar os princípios de respeito, solidariedade e cooperação, respeitando a dignidade da pessoa humana. Segundo ensina Wilson Engelmann ${ }^{82}$ :

Os desafios aumentam na medida em que este cenário é cruzado pelo multiculturalismo, próprio da vida humana em sociedade e característica dos Direitos Naturais-Humanos-Fundamentais [...]. Para tanto, a fim de construir uma efetiva "identidade cultural" assentada na dignidade da pessoa humana, como seu elemento condutor, será necessário o desenvolvimento de uma "ética da diversidade", mediante a implementação dos seguintes princípios básicos, considerados uma preliminar para a proposta de criação de marcos regulatórios para as nanotecnologias [...] (grifo nosso).

Fundamentalmente imprescindível para a construção dos marcos regulatório o ajuste aos valores ambientais e sociais da sociedade contemporânea bem como o atendimento aos ditames constitucionais, o que progressivamente vem ocorrendo, seja por meio do ativismo em prol da defesa de interesses não humanos, como também pela crescente e evolutiva mudança cultural da sociedade. "O desenvolvimento econômico deve estar vinculado à ideia de uma melhoria substancial e qualitativa (e não apenas quantitativa em termos de crescimento econômico) da qualidade de vida" ${ }^{83}$ de forma que dentro de uma ética se justifique ou se busque justificar a relevância de alguns interesses sobre outros. Ao tratar sobre o desenvolvimento da ciência e da tecnologia, professa Eliane Cristina P. Moreira ${ }^{84}$ :

O reconhecimento desse campo permite compreender por que alguns importantes elementos passam a ter menor importância nas discussões sobre a regulamentação de tecnologias como a nanotecnologia. Isto é, existem valores impostos por um dado sistema econômico que privilegia a apropriação de resultados em detrimento de outros elementos fundamentais [...] Isso ocorre porque no momento atual parece existir um único setor do qual emana a verdade, e essa verdade "precisa ser aceita". Vivemos um momento em que ciência passa a ser um oráculo da sociedade moderna (grifo nosso).

Tudo que o Direito pode dar é uma pequena contribuição ao delicado equilíbrio entre o desejo por novas tecnologias e a preocupação com outros temas

\footnotetext{
82 Ibidem, pág. 175 .

${ }^{83}$ Tiago Fensterseifer, Direitos fundamentais e proteção do ambiente: a dimensão ecológica da dignidade humana no marco jurídico constitucional do estado socioambiental de direito, Porto Alegre, Livraria do Advogado, 2008, pág. 62.

${ }^{84}$ Eliane Cristina P. Moreira, Nanotecnologia e regulação: as inter-relações entre o Direito e as ciências. [MARTINS, Paulo Roberto (org.)], Nanotecnologia sociedade e meio ambiente, São Paulo, Xamã, 2006, pág. 309
} 
que isso comporta, já que "a esfera pública convencional do Estado Democrático representativo tornou-se incapaz de lutar adequadamente contra a escalada de riscos e incertezas com que é confrontada". ${ }^{85}$ A regulação nada mais é do que um dos instrumentos que o Direito tem a oferecer. $\mathrm{O}$ desenvolvimento da regulação ou a implementação de mecanismos para que se possa saber qual o caminho que se deve seguir são objetivos do Direito, no cenário do conhecimento humano. Se ele não assumir este papel, será substituído por outras áreas do conhecimento, que aliás já estão realizando a regulação. Por conta desse movimento, atualmente não se poderá dizer que inexistem marcos regulatórios sobre as nanotecnologias. Pelo contrário, já se pode destacar a existência de um excesso de regulação e o problema que se coloca é a sua harmonização.

Os seguintes órgãos e agências estão discutindo e editando normas, padrões, diretrizes e recomendações sobre as nanotecnologias: National Institute for Health (NIH) dos Estados Unidos, National Science Foudation (NSF), ISO, OCDE, ASTM, CEN, British Standars Institution (BSI), União Europeia: Comissão Europeia e Parlamento Europeu, European Medicines Agency, CoNanomet (Europa), REACH, Nanotechnologies Industries Association (NIA), FDA, European Agency for Safety and Health at Work; OSHA - Occupational Safety and Health Administration, Health Canadá, National Nanotechnology Initiative (NNI), NIOSH, SCENIHR (Scientific Committee on Emerging and Newly Identified Health Risks), Nanoforum, Comitê de Medidas de Segurança para nanomateriais do Japão, ANF-Asia Nano Forum, Chinese Academy of Sciences, SAICM e International Council on Nanotechnology - ICON. Verifica-se que é um grupo grande de reguladores, alguns com a interferência estatal e outros não. De qualquer modo, a matéria já está regulada, sendo a grande questão na atualidade a sua harmonização.

Nos Estados Unidos, por exemplo, destacam-se as atividades regulatórias desenvolvidas no âmbito da National Nanotechnology Initiative (NNI). Tratase da reunião de agências regulatórias americanas, algumas delas acima mencionadas, que possuem orçamento próprio para o desenvolvimento das nanotecnologias sob o foco da saúde e segurança do trabalho e do meio ambiente, da propriedade intelectual, medicamentos e alimentação, riscos, parte bélica, entre outros. Sublinha-se a atuação do FDA (Food and Drug Administration) que já editou três normas específicas sobre as nanotecnologias, sendo que a última ocorreu em 27 de janeiro de 2015, e abrange "todos os dispositivos médicos que contenham materiais com partículas cujo tamanho em pelo menos uma dimensão está entre 1-100nm." Observa-se que o FDA está particularmente interessado na manipulação e controle deliberado de

${ }^{85}$ Tiago Fensterseifer, Direitos fundamentais e proteção do ambiente: a dimensão ecológica da dignidade humana no marco jurídico constitucional do estado socioambiental de direito, Porto Alegre, Livraria do Advogado, 2008, pág. 105.

Araucaria. Revista Iberoamericana de Filosofía, Política y Humanidades, año 17, n 33. Primer semestre de 2015. Pp. 151-181. ISSN 1575-6823 e-ISSN 2340-2199 doi: 10.12795/araucaria.2015.i33.07 
dimensões para produzir propriedades específicas, porque o surgimento dessas novas propriedades ou fenômenos podem levantar questões sobre a segurança, eficácia, desempenho, qualidade ou impacto na saúde pública, justificando uma avaliação mais aprofundada ${ }^{86}$.

Já na Europa, se destaca a atuação do Parlamento Europeu e da Comissão Europeia: na última semana de novembro de 2014, a maioria dos membros da Environmental, Public Health and Food Safety (EHS), do Parlamento Europeu, aprovou várias alterações no projeto de regulamentação de novos alimentos, incluindo a imposição de uma moratória sobre os novos alimentos que contêm nanomateriais ${ }^{87}$. A discussão ainda está longe de chegar a um consenso, o que evidencia a dificuldade de se criar uma regulação tradicional para as nanotecnologias. Este é um pequeno resumo do cenário regulatório internacional, onde se verifica a combinação de diversas modalidades de fontes jurídicas. Portanto, aqui está o desafio para o Direito: a regulação das nanotecnologias já existe, mas deverá ser percebida e aplicada fora do cenário positivista onde muitos juristas ainda estão vivendo, mas trabalhar na conjugação das fontes do Direito.

No caso do Brasil, estão em tramitação na Câmara dos Deputados dois projetos de lei que pretendem regular as nanotecnologias: (a) Projeto de Lei $n^{\circ} 5.133 / 2013$-cria a obrigatoriedade de inserir no rótulo de todos os produtos à base de nanotecnologias; e o Projeto de Lei $\mathrm{n}^{\mathrm{o}}$ 6.741/2013 - cria a Política Nacional de Nanotecnologia voltada ao incentivo à pesquisa, desenvolvimento tecnológico e controle pelo Poder Público dos riscos e impactos. A pesar da ausência do Direito legislado específico, existem varias áreas do Direito que trazem textos legais que poderão ser aplicados às nanotecnologias, como, por exemplo: o Código Civil, Código Penal, legislação ambiental e legislação trabalhista, sem se esquecer o arcabouço normativo - principios e regras - que estão na Constituição Federal de 1988.

\section{Conclusão}

As nanotecnologias se localizam no conjunto denominado "novas tecnologias". No entanto, dentre elas, as possibilidades abertas pelo acesso à escala nano, são sem precedentes. Existem diversos estudos demonstrando os efeitos tóxicos de algumas nanopartículas ${ }^{88}$, as questões nanotoxicológicas

\footnotetext{
${ }^{86}$ Disponível em <http://www.raps.org/Regulatory-Focus/News/2015/02/10/21294/Small-RegulationFDA-Adopts-Three-Nanotechnology-Standards-in-Last-Year/> Acesso em 10 fev. 2015.

87 Disponível em < http://www.abdi.com.br/Publicaes/Newsletter\%20Nano\%20em\%20Foco/ Dezembro\%20de\%202014/4_Dezembro_Nano_69_2014.htm> Acesso em 10 fev. 2015.

${ }^{88} \mathrm{Na}$ página do ICON - International Council on Nanotechnology se pode encontrar uma base de dados sobre as publicações atuais sobre as nanopartículas e seus efeitos, disponível em: $<$ http://icon. rice.edu/report.cfm> Acesso em 16 fev. 2015.
} 
dependem de vários fatores como o tamanho das partículas, as suas categorias - se solúveis ou não - e as características do meio onde se promovem as interações.

Os campos de aplicação das nanotecnologias são bem variados, gerando produtos com características novas. Aí se situa o desconhecido e o campo para a geração de consequências indesejadas e tóxicas. O art. 931, do Código Civil Brasileiro, fala do risco do desenvolvimento. As nanotecnologias se inserem no suporte fático desenhado por esse novo artigo da nossa legislação civil: o empresário responde pelos riscos gerados advindos dos produtos colocados no mercado. No caso das nanotecnologias, muitos dos riscos são desconhecidos. Por isso, a necessidade da gestão dos riscos, a fim de se buscar resguardar a futura responsabilidade do empresário. Aqui se tem apenas um exemplo de possibilidade de aplicação do Direito estatal vigente.

Este trabalho enfrentou o seguinte problema: sob quais condições o diálogo entre as fontes do Direito poderão aproximar as nanotecnologias das Ciências de Impacto, buscando respostas jurídicas temporalmente adequadas? Como se viu, os produtos com base nanotecnológica já estão no mercado, a produção é constante e crescente. As promessas são muitas, mas os riscos também estão emergindo. Tudo isso é gerado a partir das Ciências Duras ou Exatas, por meio das áreas como a química, física, biologia, engenharias, medicina e outras. Ao lado delas, existem as Ciências brandas ou de Impacto, que tem a função de avaliar os impactos e os desafios que as novidades geradas pelas Ciências Exatas ou de Produção estão gerando. As nanotecnologias ainda geram pouca repercussão naquelas - as Ciências de Impacto, onde se situa o Direito, por exemplo. Por isso, as questões ético-jurídicas precisarão ser levantadas e enfrentadas. Ao menos as perguntas - aqui se entendendo no modo gadameriano de falar - precisam ser lançadas.

O diálogo entre as diversas fontes do Direito poderão ser uma ponte para aproximar as duas categorias de Ciências. As proposições ético-jurídicas dependerão das informações geradas pelas Ciências Exatas. Ao mesmo tempo, o Direito deverá abrir os seus modos de produção normativa, transcendendo a fonte formal estatal por excelência, que é a lei. Haverá a necessidade de se reconhecer as produções normativas das diversas agências e organismos internacionais mencionados, interligando-as, colocando em diálogo, harmonizando-as, a fim de se conseguir lançar respostas jurídicas flexíveis e atuais, numa constância temporal alinhada com a velocidade do surgimento das novidades em escala nano. Com isso, resta confirmada a hipótese lançada inicialmente.

A tarefa não é simples, mas deverá ser enfrentada imediatamente e com criatividade, como um modo de sobrevivência do Direito e do seu modo de produção do jurídico. 


\section{Referências}

AGÊNCIA BRASILEIRA DE DESENVOLVIMENTO INDUSTRIAL (ABDI). Cartilha sobre nanotecnologia, Disponível em < http://www. abdi.com.br/Estudo/Cartilha\%20nanotecnologia.pdf>, Acesso em: 11 fev. 2015.

AGÊNCIA BRASILEIRA DE DESENVOLVIMENTO INDUSTRIAL (ABDI). Panorama de Nanotecnologia, Disponível em: <ww.abdi.com. $\mathrm{br} /$ Estudo/Panorama\%20de\%20Nanotecnologia.pdf $>$, Acesso em: $11 \mathrm{de}$ fev. 2015.

AGÊNCIA BRASILEIRA DE DESENVOLVIMENTO INDUSTRIAL (ABDI). Nanoalimentos e uma nova definição legal de nanomateriais engenheirados. Disponível em < http://www.abdi.com.br/Publicaes/ Newsletter\%20Nano\%20em\%20Foco/Dezembro\%20de\%202014/4 Dezembro_Nano_69_2014.htm> Acesso em 10 fev. 2015.

BRAGATO, Fernanda. Os Direitos do Humano em Risco na Sociedade Tecnocientífica. IN: ENGELMANN, Wilson (Org). As Novas Tecnologias e os Direitos Humanos: Os Desafios e as Possibilidades para Construir uma Perspectiva Transdisciplinar, Paraná, Honoris Causa, 2011.

BRASIL, Constituição (1988), Constituição da República Federativa do Brasil de 1988. Brasília, DF, 5 de outubro 1988, Disponível em: <http://www. planalto.gov.br/ccivil_03/constituicao/constitui\% C3\%A7ao.htm>. Acesso em 13 fev. 2015.

CARVALHO, Délton Winter de. Dano ambiental futuro: a responsabilização civil pelo risco ambiental, Rio de Janeiro, Forense Universitária, 2008.

, Délton Winter de. Por uma necessária introdução ao direito dos desastres ambiental, Revista de Direito Ambiental, v. 67, p. 107-145, 2012.

CAVALHEIRO, Esper A. A nova convergência da ciência e da tecnologia. Novos estudos - CEBRAP, n.78, p. 23-30. 2007. Disponível em: <http:// www.scielo.br/pdf/nec/n78/04.pdf >. Acesso em: 08 fev. 2015.

DALCOMONI, Sônia Maria, Inter-relações fundamentais para o desenvolvimento sustentável. [MARTINS, Paulo Roberto (org.)], Nanotecnologia, sociedade e meio ambiente, São Paulo, Xamã, 2006.

DURAN, Nelson; MATTOSO, Luiz Henrique Capparelli; MORAIS, Paulo Cezar de. Nanotecnologia: introdução, preparação e caracterização de nanomateriais e exemplos de aplicação, São Paulo, Artliber Editora, 2006.

ENGELMANN, Wilson Engelmann. As Nanotecnologias e a Gestão Transdisciplinar da Inovação. IN: ,Wilson (Org), As Novas Tecnologias e os Direitos Humanos: Os Desafios e as Possibilidades para Construir uma Perspectiva Transdisciplinar, Paraná, Honoris Causa, 
2011.

, Wilson; FLORES, André Stringhi; WEYERMÜLLER, André Rafael. Nanotecnologias, Marcos Regulatórios e Direito Ambiental, Curitiba, Honoris Causa, 2010.

, Wilson. As nanotecnologias e suas interações com o Meio Ambiente: dos riscos aos tópicos associados ao nanoambiente. VI Simpósio Dano Ambiental na Sociedade de Risco, 2011, Florianópolis, Anais do VI Simpósio Dano Ambiental na Sociedade de Risco, Florianópolis, FUNJAB, 2011, v. 1CD.

FENSTERSEIFER, Tiago. Direitos fundamentais e proteção do ambiente: a dimensão ecológica da dignidade humana no marco jurídico constitucional do estado socioambiental de direito, Porto Alegre, Livraria do Advogado, 2008.

FREITAS, Carlos Machado de.Avaliação de Riscos dos Transgênicos Orientada pelo Princípio da Precaução. IN: TELLES, José Luiz; VALLE, Silvio (orgs.), Bioética e biorisco: abordagem transdisciplinar, Rio de Janeiro, Interciência, 2003.

FREITAS, Juarez. Sustentabilidade: direito ao futuro. 1. ed., 1ª. reimp., Belo Horizonte, Fórum, 2011.

FRANK, H. Quina. Nanotecnologia e o meio ambiente: perspectivas e riscos, Química Nova, São Paulo, v.27, n. 6, p.1028-29, 2004, Disponível em: $<$ http://www.scielo.br/pdf/qn/v27n6/22297.pdf $>$. Acesso em: 28 jan. 2015.

GADAMER, Hans-Georg. Verdade e Método, Traços fundamentais de uma hermenêutica filosófica, 4. ed, [Tradução de Flávio Paulo Meurer], Petrópolis, Vozes, 2002, vol. I.

INTERNATIONAL COUNCIL ON NANOTECHNOLOGY (ICON). NanoEHS Database Analysis Tool. Disponível em: $<\mathrm{http}$ ://icon.rice.edu/report. $\mathrm{cfm}>$. Acesso em 16 fev. 2015.

JAMIESON, Dale. Ética e meio ambiente: uma introdução, [Dale Jamieson; tradução de André Luiz de Alvarenga], São Paulo, Editora Senac São Paulo, 2010.

JONAS. Hans. O princípio da responsabilidade: ensaio de uma ética para a civilização tecnológica [Hans Jonas; tradução do original alemão Marijane Lisboa, Luiz Barros Montez], Rio de Janeiro, Contraponto Ed. PUC-Rio, 2006.

LEMOS, Patrícia Faga Iglecias. Resíduo sólido e responsabilidade civil pósconsumo, 2. ed. rev. e amp., São Paulo, Revista dos Tribunais, 2012.

MACHADO, Paulo Affonso Leme. Direito ambiental brasileiro, 18. ed., rev. atual. e ampl., São Paulo, Malheiros, 2010.

MARTINS, Paulo Roberto. Nanotecnologia, sociedade e meio ambiente, São 
Paulo, Xamã, 2006.

MOREIRA, Eliane Cristina P. Nanotecnologia e regulação: as inter-relações entre o Direito e as ciências. IN: MARTINS, Paulo Roberto (org.). Nanotecnologia sociedade e meio ambiente, São Paulo, Xamã, 2006.

NEDEL, José. Ética aplicada: Pontos e contrapontos, São Leopoldo, Editora Unisinos.

REGULATORY AFFAIRS PROFESSIONALS SOCIETTY (RAPS). Small Regulation: FDA Adopts Three Nanotechnology Standards in Last Year. Disponível em <http://www.raps.org/Regulatory-Focus/ News/2015/02/10/21294/Small-Regulation-FDA-Adopts-ThreeNanotechnology-Standards-in-Last-Year/> Acesso em 10 fev. 2015.

SCHULZ, Peter Alexander Bleinroth. A encruzilhada da nanotecnologia: inovação, tecnologia e riscos, Rio de Janeiro, Vieira \& Lent, 2009.

SINGER, Peter. Ética Prática, [Tradução Jefferson Luiz Camargo], 3. ed., São Paulo, Martins Fontes, 2002.

TOMA, Henrique E. Interfaces e organização da pesquisa no Brasil: da Química à Nanotecnologia, Química Nova, São Paulo, vol. 28, suppl., pág. S48-S51, 2005. Disponível em:< http://www.scielo.br/pdf/qn/ v28s0/26775.pdf $>$. Acesso em: 08 fev. 2015. 
